\title{
Development of Aspect Morphology in Korean
}

\author{
Hae-Young Kim · Youngon Choi* \\ (Duke University · Chung-Ang University)
}

\begin{abstract}
Hae-Young Kim, Youngon Choi (2016), Development of Aspect Morphology in Korean. Journal of Language Sciences 23(4), 203-225. The present study examined the development of aspect marking in Korean with a focus on $-k o$ iss ${ }^{-}$and $-a$ is $S^{-}$imperfective markers, compared with progressive and perfective markers. First, we examined the comprehension accuracy of 3-4-year-old Korean-learning children, while observing their online interpretation patterns via their eye-fixation. Second, 3-4-year-olds' production of aspect markers was elicited, using pictures/videos that portrayed various aspects of events. Both groups of children comprehended progressive meanings better than the perfective/resultative meanings. Accuracy between the imperfective markers didn't differ but 4-year-olds were more accurate than 3-year-olds. In production, 4-year-olds were more accurate in producing -ko iss ${ }^{-}$than $-a$ iss ${ }^{-}$, while 3 -year-olds were less accurate in using both markers. Eye-gaze patterns showed that children were faster in identifying the resultative $-k o$ is $s^{-}$than $-a$ iss $s^{-}$event. Taken together, these results suggest that Korean children may begin extending the progressive $-k o$ iss ${ }^{-}$form into the result state before they fully acquire a new resultative form, indicating polysemous extension of the existing form as the acquisition mechanism of aspect morphology. (Duke University · Chung-Ang University)
\end{abstract}

Key Words: aspect morphology, development, Korean, comprehension, production, eye-gaze pattern, imperfective, resultative

\section{Introduction}

Three Korean aspect markers, perfective -ass-, progressive -ko iss ${ }^{-}$ and resultative $-a$ is $S^{-}$, originated from the same source, the connective - $a$ ('and') plus the verb is(i) ('exist'). According to Kim(2009), historically

* Hae-Young Kim is the first author and Youngon Choi is the corresponding author. We thank all the children and their parents for their participation and 고연정, 주나래 for their assistance in this study. 
- $a$ iss ${ }^{-}$carried both progressive and resultative meanings in Middle Korean, but it was replaced by - $k o$ iss-, triggered by a massive increase of $-k o$ in the connective domain. In present day Korean, the progressive - ko iss ${ }^{-}$carries the dual function of in-progress and resultant duration, while - $a$ iss ${ }^{-}$signifies resultant duration with intransitive verbs. Whereas historically - a iss ${ }^{-}$had perfective meaning and the anterior/perfect marker -ass- derived from it, it now has only result state interpretation in modern Korean.

The two durative markers, $-k o$ iss ${ }^{-}$and $-a$ is $S^{-}$, present an interesting case for investigating changes in form-meaning mapping in language development. In the perspective of the learner, $-k o$ is ${ }^{-}$is polysemous with two distinct meanings, action-in-progress and result state. Meanwhile, with regard to result state marking, there is a complementary distribution between $-k o$ iss ${ }^{-}$and $-a$ iss ${ }^{-}$based on transitivity of the main verb; - $k o i^{-} s^{-}$is restricted to transitive verbs while $-a$ is $^{-}$is used with intransitive verbs. Acquisition of imperfective markers must thus entail: (i) extension of the meaning of the - ko iss ${ }^{-}$marker from action-in-progress to result state meaning, and (ii) the learning of the semantic and syntactic environments of the result state meaning in which - $a$ iss - marker is used(Lee and Kim, 2007; Shin, 2005). In this paper, we aimed to shed light on the development of aspectual marking in child Korean, by examining how children proceed with two possible learning mechanisms(described below), through investigating this pair of durative markers.

Let us begin with the functions and lexico-semantic constraints of the two Korean imperfective markers. The imperfective $-k o$ iss ${ }^{-}$construction can express progressive or resultative meanings in interaction with the lexical aspect of the co-occurring verb. With activity and accomplishment verbs, it has action-in-progress meaning that refers to the internal duration of the event, as shown in (1). Unlike the English progressive or the Japanese -te $i^{-}$, however, $-k o$ iss ${ }^{-}$is not obligatory for an on-going event interpretation, and the simple present can refer to on-going events in Korean. The optionality of - $\mathrm{ko}$ iss $^{-}$the progressive interpretation 
means that it is not reliably there in the input data for acquisition, which likely poses difficulty to or brings about a delay of learning.

(1) 수지는 차를 한 잔 마시고 있다.

Suzy-nun cha-lul han can masi-ko iss-ta.

Suzy -Top tea-Acc one cup drink-Prog-Dec

'Suzy is drinking a cup of tea.'

With some accomplishment and achievement verbs, typically verbs of contact and wearing, $-k o$ iss ${ }^{-}$can express result state meaning that marks the state of the agent after the completion of the event. These verbs describe a transition of some kind, and thus easily trigger a result state interpretation. Without any context, however, - ko iss- used with an accomplishment verbs, as in (2a), can have either progressive('is putting on') or result state('is wearing') interpretation, but with a disambiguating context such as (2b), result state interpretation can be clearly obtained:

a. 수지는 선글라스를 끼고 있다.

Suzy-nun sen kullas-lul kki-ko iss-ta.

Suzy-Top sunglasses-Acc wear-Prog-Dec.

'Suzy is wearing sunglasses.'

b. 어디를 보는지 모르겠다.

Eti-lul po-nun-ci molu-kess-ta .

where-Acc see-Present-Comp not know-Fut-Dec.

'It's hard to see where she looks.'

Overlap between the progressive and the resultative has been found crosslinguisticallly(Kim, 2009). Japanese - te iru- similarly carries dual functions of resultant duration as well as internal duration(Ryu, Horie and Shirai, 2016), and a parallel is found in English wearing and position verbs in the progressive form, which have resultative interpretation(Smith, 1991, 
1997). However, in Korean, $-k o$ iss- is optional for expressing result state as it is for progressive meaning marking, and the same situation can be expressed by the perfective - ass- (e.g. kki-ess-ta (꼈다) would have the same meaning in (2a-This explains why L1 Korean speakers produced ko iss- $84 \%$ of the time in the pilot testing of our experimental materials as described below). The difference is that with $-k o$ iss-, it is the asserted meaning, while with - ass- it is by implicature, which would be cancelled with the use of a past time adverbial(Lee and Kim, 2007).

The resultative function of $-\mathrm{ko}_{\mathrm{iss}}{ }^{-}$is limited to telic transitive verbs which describe an action whose completion and result affects the state of the agent(Kim, 2009), verbs of contact and wearing being the most common. On the other hand, $-a$ iss- selects intransitive telic verbs to express result state meaning, typically 'abstract' achievement verbs whose culmination point is followed by a sustained post-event phase(Kim, 2013). More frequently with achievement verbs depicting change of state or locomotion(e.g. 녹다 melt, 앉다 sit, 떨어지다 fall), it describes a persisting state resulting from a completed action, as in (3)

(3) 컵이 바닥에 떨어져 있다.

Kep-i patak-ey tteleci-a iss-ta.

Cup-Nom floor-Loc drop-Resl-Dec

'The cup has fallen on the floor'

Differences in complementation restriction of $-\mathrm{kO}^{\mathrm{i}} \mathrm{SS}^{-}$and $-\mathrm{a}$ iss- are correlated with their aspectual properties(Lee, 2008). ${ }^{-K o}$ iss- is regarded to be a more dynamic durative whereas $-a$ is $S^{-}$is a stative durative, in that the result states expressed with $-k o$ is $s^{-}$indicate a temporary state that inherently assumes an upcoming change of state(Lee, 1991). Moreover, they are consciously and volitionally initiated and maintained by an agent, whereas those expressed with $-a$ iss- are not(Lee, 1993). In Lee's(2008) view, this semantic analysis is aligned with the syntactic structure of $-k o$ iss that selects transitive and unergative verbs and $-a$ iss ${ }^{-}$that selects unaccusative and passive verbs. The lexico-semantic 
restrictions of $-k O i S S^{-}$and $-a$ is $S^{-}$are summarized in Figure 1.

Figure 1. Description of Lexico-semantic Constraints of -ko issand - a iss - Markers.

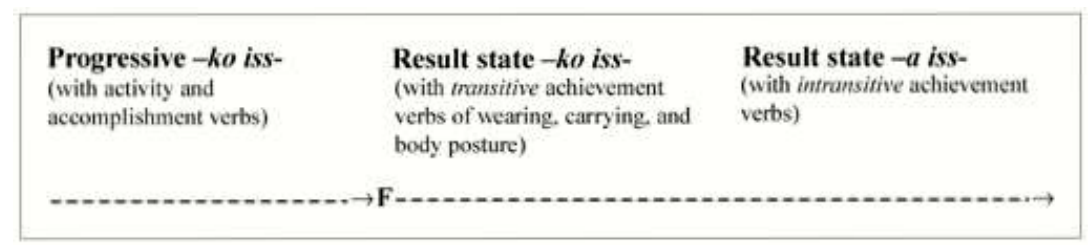

* F here indicates final point of a situation or an event, or a change in a state.

(Lee and Kim, 2007)

In the acquisition of the dual functions of $-k o$ iss ${ }^{-}$, we expect progressive meaning to develop earlier than result state meaning, on the basis of the predictions of the Aspect Hypothesis, a theory of the morphological development of tense/aspect marking(Andersen and Shirai, 1996). The Aspect Hypothesis is developed from extensive data demonstrating strong associations of grammatical tense/aspect marking and lexical aspects of the verbs. In the development data of many languages, past tense or perfective aspect is marked first with achievement(e.g. break) and accomplishment verbs(e.g. build a car), which describe events that have clear end points $([+$ telic $])$. Then, it gradually spreads to activities(e.g. sing, play the piano) and states(e.g. live) that describe situations without inherent end points([-telic]). Progressive marking in English, on the other hand, proceeds from activity verbs to accomplishment and achievement verbs.

Shirai and Andersen's(1995) prototype account explains early association of grammatical tense and aspect with particular lexical aspect as a function of semantic congruence between them. Achievement verbs(e.g. drop, break) can be said to be the prototype of past tense in that they are [+punctual], [+telic], [+result]. Meanwhile, activity verbs(e.g. sing, play the piano) are the prototype of progressive aspect, with their semantic features of [-telic], [+durative], [+dynamic]. Action-in-progress 
interpretation of Korean $-k o$ iss- too is typically obtained with activity verbs, whereas result state meaning arises with achievement verbs. Then, the mechanism that enables the learner to generalize tense and aspect morphology to other verb types beyond prototype associations has received little attention(Bardovi-Harlig, 2005). Imperfective, in particular, presents a challenge in this regard since it encodes a broader range of meanings than past tense/perfective, such as habitual, continuous, progressive, durative and iterative situations.

In an effort to address the question of how the learner extends the meaning of $-k o$ iss- from the prototype association of action-in-progress to a less congruent association of result state, we can postulate two paths of development from action-in-progress to result state meaning: (i) the new meaning of the familiar form $-k o$ iss ${ }^{-}$is incorporated prior to acquisition of the alternate form $-a$ iss $^{-}$, or (ii) the new form and meaning of $-a$ iss ${ }^{-}$is learned first and triggers the extension of the meaning of $-k_{0} i^{-} s^{-}$. In some sense, these correspond with two competing principles of form-meaning mapping, polysemy and isomorphism. Polysemy refers to a lexical relation in which a single linguistic form has different but related meanings(Zawada, 2007), and isomorphism refers a one-to-one association between linguistic form and its content(Fried, 2007; Markman and Wachtel, 1988). If polysemy prevails, the learner will extend the meaning of the form $-k o$ iss- prior to or simultaneous with the learning of $-a$ iss ${ }^{-}$. If isomorphism is the main mechanism, the learner will confine -ko iss- to action-in-progress meaning while they learn the new form and result state meaning of $-a$ iss ${ }^{-}$. Research on lexical development showed that young children are capable of making an extension to a different meaning in polysemous situations, that is when the alternate meaning is related to the baseline meaning, compared to homophonous situations where the meanings are unrelated(e.g. Srinivasan and Snedeker, 2011). This suggests the existence of a generative structure in the linguistic representation, developing or stable, which is conducive to acquisition of polysemous meanings of a linguistic form.

Previous research has shown that both L1 and L2 Korean learners 
acquire progressive meaning before result state meaning in Korean, but the acquisition pattern of $-k o$ is ${ }^{-}$and $-a$ iss ${ }^{-}$for result state has not been understood well. Shin(2005) demonstrated that children under the age of 2:6 used default verb forms for present progressive meaning and the past tense marker - ass ${ }^{-}$with telic verbs for perfective meaning. Lee and Kim(2007) investigating L1 English learners of L2 Korean observed that the progressive meaning of $-k o$ is $s^{-}$was easier for learners but found no clear pattern with respect to result state meaning. Their hypothesis that a new form - a iss- would trigger the learning of result state meaning based on the principle of isomorphism was not borne out. In fact, many learners seemed to follow an alternative route of learning a new aspectual meaning from the familiar marker $-k o$ iss ${ }^{-}$. On the other hand, a recent study on Japanese learners of Korean by Ryu et al.(2016) showed that result state - ko iss ${ }^{-}$is acquired before - a iss- ${ }^{-}$. They explained that such acquisition sequence is due to L1 Japanese transfer, i.e. analogy with the Japanese aspect marker - te iru which is used both for progressive and resultative.

Our study focuses on the development of viewpoint aspect marking in child Korean, that is, how children learn to use grammatical aspectual markers to describe a situation as a bounded whole(i.e. 입었다) or as an unbounded one(i.e. 입고 있다). More specifically, how do Korean learners acquire the imperfective meanings of $-k o$ iss ${ }^{-}$comprising action in progress(e.g. She is choosing glasses, 안경을 고르고 있다) and result state(e.g. She is wearing glasses, 안경을 쓰고 있다)? How do they learn that $-a$ iss ${ }^{-}$encodes result state only(e.g. She is sitting on the floor 바닥 에 앉아 있다), unlike -ko iss ${ }^{-}$? How do they figure out that the two forms have complementary distribution for result state meaning; -ko issis used with transitive verbs while $-a$ iss ${ }^{-}$is used with intransitive verbs?

Our working hypotheses for this study are as follows, grounded on the studies of development of tense and aspect morphology(Anderson and Shirai, 1996) and the literature on polysemy in lexical development in children(Srinivasan and Snedeker, 2011): (i) The progressive meaning of - 
ko iss- develops before the resultative meaning, as predicted by the Aspect Hypotheses and attested by previous studies. (ii) The meaning of - $k o$ iss- expands to the resultative, prior to or independent of learning of - $a$ iss ${ }^{-}$. Research on lexical development suggests that young children are capable of shifting to a different meaning from the basic meaning (Srinivasan and Snedeker, 2011). That is, the acquisition of a novel meaning does not have to be mediated by a separate form. (iii) The resultative $-k_{0} i_{S S^{-}}$is over-extended to intransitive verbs initially. Respective lexical-semantic environments of $-k^{-} i_{S S^{-}}$and $-a$ iss ${ }^{-}$are only gradually grasped.

We conducted two experiments that presented distinct aspectual meanings(result state, progressive and perfective) established by contextualized verbal and visual stimuli. Experiment 1 examined comprehension using a sentence-picture matching task with $3^{-}$and 4-year-olds while recording their eye-gazes. Experiment 2 looked at production, with a picture/video description task to elicit the markers from 3-4-year-olds. The assumption was that varying performances shown in cross-sectional group data would reflect developmental trends. That is, comparative accuracy, ease or frequency of comprehension and production of the target form/function parallels the stage of acquisition.

\section{Experiment 1: Comprehension}

The first experiment examined the accuracy and speed of comprehension of four aspect conditions: perfective -ass-, progressive $k o$ iss-, resultative $-k o$ is $s^{-}$and resultative $-a$ iss-. The comprehension was examined by a sentence-picture matching task, with the percentage of correct responses as the dependent measure. We also recorded eye-fixation patterns as children select the picture but these data are only partial due to several children's recordings were not completed. 


\subsection{Participants}

A total of 13 3-year-olds $(3 ; 3-3 ; 10, \mathrm{f}=4)$ and eighteen 4-year-olds $(4 ; 0-5 ; 0, \mathrm{f}=10)$ participated in the task. Two additional 3-year-olds' data were not included in the final analyses because their less than 50\% accuracy during practice indicated they did not understand the task.

\subsection{Stimuli and Procedure}

Each of the four different aspect conditions included six tokens, totaling twenty-four target sentences. The progressive ${ }^{-k o}$ iss- sentences consisted of activity and accomplishment verbs, such as 'sleep', 'watch TV', 'color (a shape)', 'patch (broken pieces)', 'open (an umbrella)', and 'pour (liquid in a cup)'. The $-a$ iss- resultative sentences included two posture verbs (anc- 앉- 'sit'; ilese- 일어서- 'stand up'), two motion verbs ( swum- 숨- 'hide'; ollaka- 올라가- 'climb up'), and change of state verbs (ccieci- 찢어지- 'be torn'; kkaeci- 깨어지- 'be broken'). The -ko issresultative sentences included two posture verbs (manseyha- 만세하'stretch arms'; appa taliha- 아빠 다리 하- 'cross one's legs'), two carrying verbs (an- 안- 'hold in one's front'; tul- 들- 'hold up'), and two wearing verbs ( $\sin ^{-}$신- 'put on (shoes)'; ip- 입- 'put on (clothes)). The perfective - ass- sentences included two achievement and four accomplishment verbs (ttelettuli- 떨어뜨리- 'drop (a spoon)'; tenci- 던지- 'throw (a ball)'; mek먹- 'eat (an ice cream cone)'; ssis- 씻- 'wash (the hands)'; calu- 자르'cut out (a shape)'; yel- 열- 'open (the zipper of a wallet)'). The presentation order of the conditions was counterbalanced using four different presentation lists.

The visual stimuli consisted of pairs of the target picture and a distracter picture, as shown in Figure 2. The target picture described the intended aspectual meaning whereas the distracter presented one of the other aspectual conditions. For example, the perfective target was distracted with the progressive ('has eaten an ice cream cone' in contrast with 'is eating an ice cream cone'), as illustrated in Figure 2a. Although - ass- could have multiple functions such as simple past, anterior, and 
perfective(Oh, 2003 but see Jeong, 2013 and Yoon, 2015 for different analyses of -ass-), the perfective meaning was clearly established in this experimental context. The progressive target was distracted with the perfective or the preliminary phase (e.g. 'is watching TV' in contrast to 'is about to watch TV' 7 . The result state was distracted with the progressive or the preliminary phase. Three practice trials preceded the target trials.

\section{Figure 2A-B. Examples of the Target and Distracter Picture}

\section{A. Perfective Sentence}

'The girl has eaten the ice cream, 아이스크림을 먹었어요.'

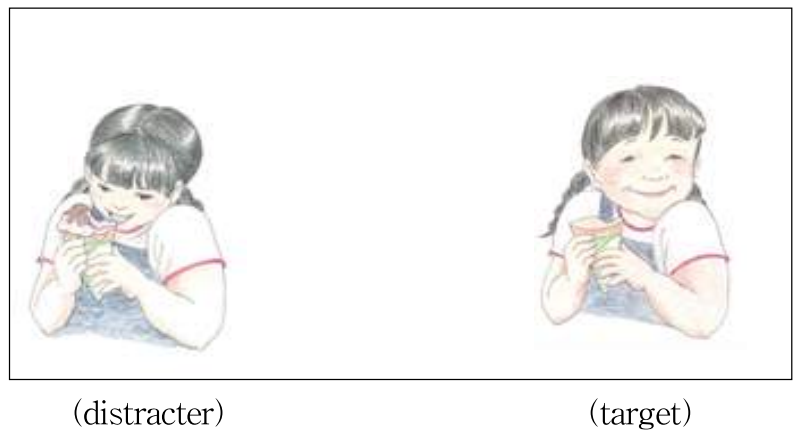

B. Resultative Sentence

'The cat has climbed up the tree, 고양이가 나무에 올라가 있어요.'

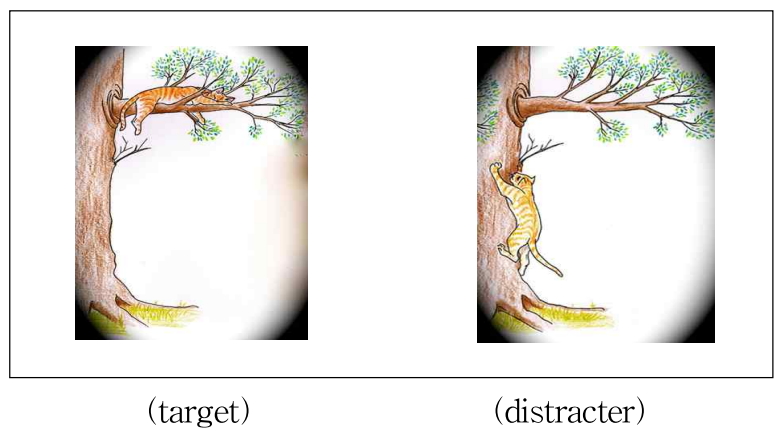

Children were asked to point to a picture that matches the sentence they heard. For example, as illustrated in Figure 2, the children heard the 
stimulus, "The cat has climbed up the tree (고양이가 나무에 올라가 있어 요), while being presented with the two pictures, one depicting the progressive situation where a cat chased by a dog is climbing up a tree and the other the result state situation in which the cat is sitting on a high branch of the tree with the dog at the bottom of the tree. While they were listening and looking at pictures, their eye-movements were video-recorded using a digital camera on top of the monitor in front of them.

\subsection{Results}

Preliminary analyses revealed that sex of the children and presentation list were not significant factors(Fs $<1$, ps $>.58$ ), therefore these were not included in the following analyses. Figure 3 summarizes comprehension scores by age group and by four aspect marker conditions.

First, we conducted a mixed-model analysis of variance on the percent accuracy measure with 3 aspect condition(progressive, perfective, resultative) as a within-participant variable, and 2 age groups $(3,4)$ as a between-participant variable. The main effect of aspect condition was significant $(\mathrm{F}(2,58)=5.434, \mathrm{p}<.01)$, however, neither the main effect of age group nor the interaction effect between the aspect condition and age groups was significant(Fs $<2.2$, ps $>.15$ ).

However, when we compared progressive -ko iss $^{-}$and resultative $-\mathrm{ko}$ iss-, we found that 4-year-olds were relatively more accurate than $3-$ year-olds $(\mathrm{F}(1,29)=3.855, \mathrm{p}=.059)$ and both age groups of children understood progressive marking better than resultative marking $(F(1,29)=$ 7.570, $p=.01$ ). The two imperfective markers did not significantly differ in the overall comprehension $\operatorname{score}(F(1,29)=.728, p=.400)$, but 4-year-olds were overall more accurate than 3-year-olds in understanding these $\operatorname{markers}(F(1,29)=4.589, p<.05)$.

A post-hoc analysis showed that the children's understanding of the two resultatives varied with lexical verb types. For instance, the accuracy was low for the resultative -ko iss ${ }^{-}$used with 'wearing' verbs $(36.2 \%)$ compared to posture(96.2\%) or carrying verbs(90.1\%). The effects of the 
verbs were significant statistically $(F(2,58)=49.794, p<.001)$, and but not the effects of age or interaction between the two factors. Note that lower accuracy observed for the 'wearing' verbs was due to that many children interpreted the result state - $k o$ iss $s^{-}$I 'She is wearing a yellow dress' and 'He is wearing white pants' as progressive aspect.

Figure 3. Mean Percent Accuracy in Selecting the Sentence-matching Pictures, split by Age Group and Four Aspect Marker Conditions.

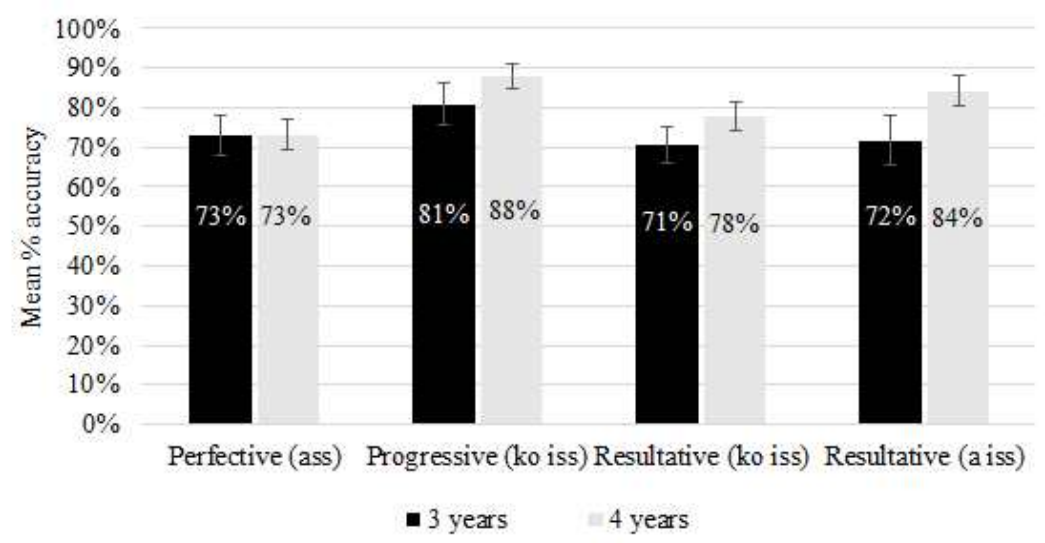

* Error bars indicate standard error of the mean.

The effects of specific verb types were also significant for the resultative $-a$ iss- too $(F(2,58)=5.650, p<.01)$, while the age effect was $\operatorname{marginal}(F(2,58)=3.083, p=.09)$. Comprehension was poorer when the verb involved 'location'(66.3\%) as compared to 'posture'(81.5\%) or 'state'(86.2\%).

As mentioned earlier, we also observed the children's eye-fixation patterns as they listen to the sentence. Unfortunately, only partial data were collected due to mechanical failures and experimenter errors. So we were only able to see the patterns of four 4-year-olds and 11 3-year-olds. So keep in mind that our eye-gaze data reported here is to show the trends and is not yet definitive. Still, considering that final picture 
selection only reflects offline interpretation and does not reflect online interpretation as the sentence unfolds (e.g., Tanenhaus, Spivey-Knowlton and Sedivy, 1995), we believe that exploring children's online interpretation pattern as they hear the markers would be quite informative to see the child's moment-by-moment analysis of the markers.

Figure $4 \mathrm{~A}-\mathrm{B}$ shows the eye-gaze patterns for both age groups in two imperfective conditions. As shown in Figure 4, when eye-fixations to target pictures were compared between the resultative ${ }^{-k o} i_{S S^{-}}$and the resultative $-a$ is ${ }^{-}$, fixations to target pictures tended to converge more rapidly with $-k o$ is ${ }^{-}$than $-a$ iss ${ }^{-}$for both age groups. What this might suggest is that the children may be faster in processing and understanding the sentences including -ko iss - than those with - a isS-.

Figure 4A-B. Mean Eye-gaze Patterns Charted for 4-year-olds (A) and 3-year-olds (B) around onset of verb until they selected the picture.

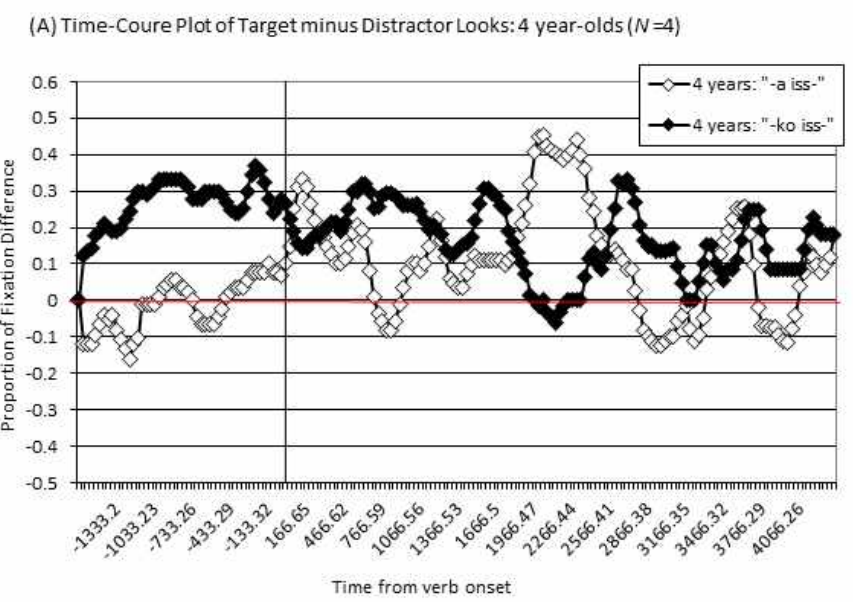


(B) Time-Course Plot of Target minus Distractor Looks: 3 year-olds $(N=11)$

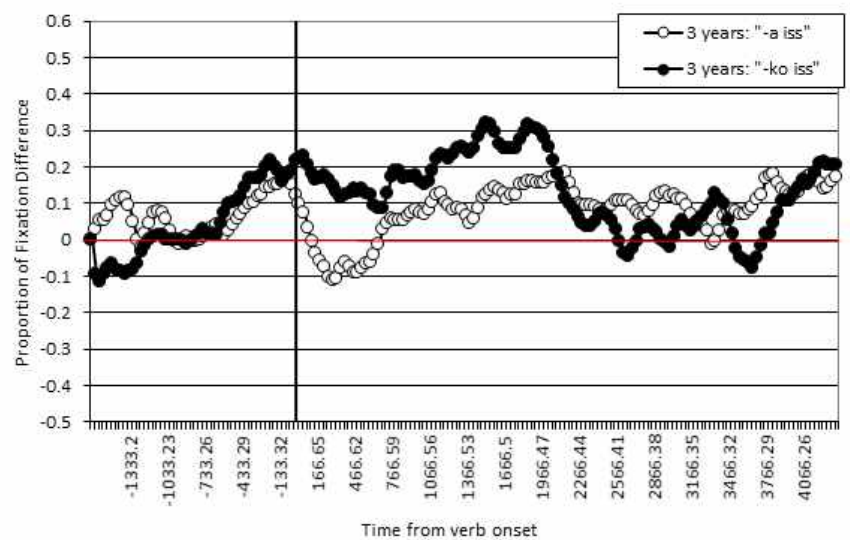

* Positive numbers indicate more looks to the targets than the distracters.

\section{Experiment 2: Production}

The second experiment investigated children's expression of three aspect conditions: perfective - ass ${ }^{-}$, resultative $-k o$ is ${ }^{-}$and resultative $-a$ iss ${ }^{-}$. The elicitation task was designed with pictures and videos of situations of which the description would require the target aspectual markers.

\subsection{Participants}

Fifteen 4-year-olds(4:0-4:10, f=5) and fourteen 3-year-olds (3:3-3:10, $\mathrm{f}=4$ ) participated in the production tasks. Three additional 3-year-olds participated but they were presented with older children's version of the task and therefore not included in the final analyses.

\subsection{Stimuli and procedure}

Children's responses were audio-recorded, transcribed and coded. The dependent measure was percentage of correct aspect markers in the given 
situations. The elicitation task consisted of three-part picture/video description tasks; two parts targeted the resultatives and one the perfective. In Part A which targeted the resultatives(e.g. She is wearing gloves, 장갑을 끼고 있어요), children were presented three similar pictures and asked to identify and describe a different one(e.g., Two pictures show a woman holding the gloves while the other one displayed the woman wearing the gloves). In Part B which also targeted the resultatives (e.g. She is lying down, 누워 있어요), children were shown two pictures one by one in sequence and asked to describe the change of state in the second picture (e.g., the woman was standing in the first picture but lying down in the second one). In Part $\mathrm{C}$ which targeted the perfective-ass-, children were shown a video and asked to describe the ending(e.g. she has taken off socks, 양말을 벗었어요). The video presented a bounded situation involving a telic verb that describes an initial phase(e.g. with socks on the feet), in-progress phase(e.g. pulling out socks one by one from the feet), and the culmination point(e.g. both socks off). Other situations include opening an umbrella, putting on gloves, walking up to the top of a stepper and the like. The perfective marker use would be the unmarked choice, as verified by L1 speakers in the pilot test below, unless the speaker chose to do a narrative live report using present tense. That is, in this experimental design, if - ass- was used in describing the ending of the video, it was to express the perfective aspect, not simple past or anterior.

For 4-year-olds, each part had six stimuli, involving three lexical verb types used with $-a$ iss-(location, posture, and state verbs) and - ko iss(carrying, posture, and wearing verbs). But for 3-year-olds, each part had four stimuli, after considering the fact that younger ones will have shorter attention span to complete the task. 
Figure 5A-B. Examples of Pictures used to Elicit Target Resultative Markers.

A. An Example of Pictures shown for Part A to Describe an Odd one

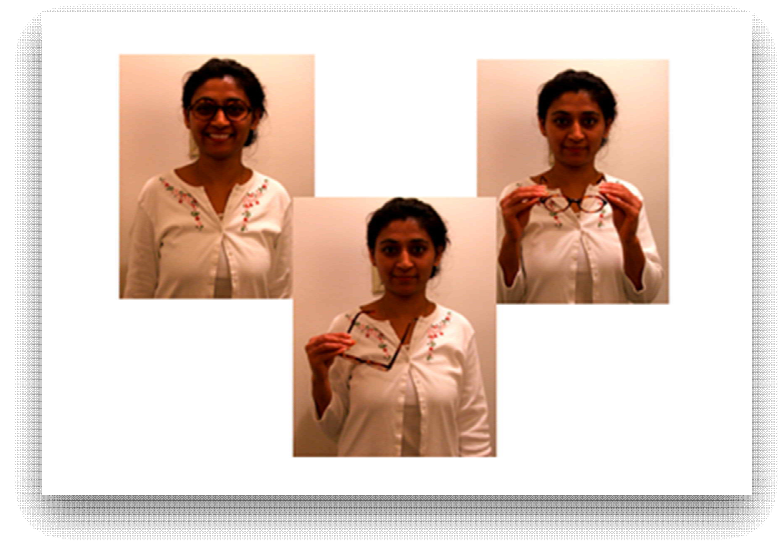

B. An Example of Pictures shown for Part B to Illustrate the Change of State.

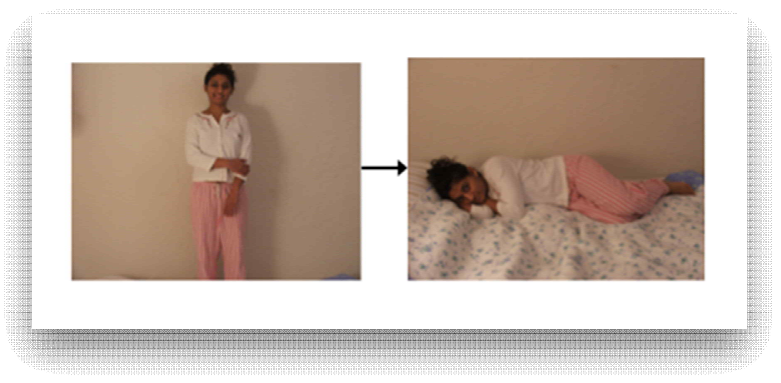

The stimuli had been pilot-tested with 10 adults to ensure that the aspectual conditions be interpreted as intended. Part A successfully elicited result state markers and Part $\mathrm{C}$ perfective markers whereas Part B showed mixed results. The adults produced the target markers $84 \%$ of the time in the - $k$ o iss - contexts, $82 \%$ in the - $a$ iss- contexts, and $92 \%$ in the - ass ${ }^{-}$contexts. The relatively low production of the resultative markers was not unexpected given that the forms are not required to express the intended meaning, as described above. Therefore, we decided 
that the materials established the target conditions successfully enough.

In the experiment with children, the three parts were presented in different configurations in order to counterbalance the ordering effects. Our goal was to get one token of the target form from each picture or video, but the children produced more tokens as they often gave descriptions of situations beyond the target picture or scene. Also, children used different lexical verbs in resultative contexts, which could not occur with the result state markers(e.g. tteletturi- 떨어뜨리- 'drop'; mul-ul ssot- 물 쏟- 'spill water'), and thus we classified these as the perfective context. Consequently, we had larger numbers of data points than we planned and varying numbers of tokens for each context.

\subsection{Results}

We performed a 2x2 mixed-model ANOVA on percent accurate production measure as a dependent variable, with age group $(3,4)$ as a between-participant and aspect condition (perfective, resultative - ko iss-, resultative - a iss-) as a within-participant factor. Aspect condition was a significant factor $(F(2,54)=54.728, p<.001)$ and the effect of age was marginally significant $(F(1,27)=3.268, p=.082)$. However, the interaction between the two were not $\operatorname{significant}(F(1,27)=1.777, p=.194)$.

As summarized in Table 1, both age groups of children produced perfective targets very accurately overall and their production accuracy was much higher than the two imperfective markers. Between the two resultative markers, 4-year-olds' accuracy for - ko iss ${ }^{-}$was significantly higher than the resultative $-a$ is $-(F(1,13)=5.774, p<.05)$ while those of 3 -year-olds were comparably low for both $\operatorname{markers}(F<1)$. 


\section{Table 1. Mean \% Correct Production (and Standard Error) by Age Group and Aspect Condition.}

\begin{tabular}{cccc} 
& & Aspect condition & \\
& $\begin{array}{c}\text { Perfective } \\
-a s S^{-}\end{array}$ & $\begin{array}{c}\text { Resultative } \\
-k o \text { iss }\end{array}$ & Resultative \\
& $86.5(3.6)$ & $32.7(7.7)$ & $-a$ iss $^{-}$ \\
\hline 3 years & $91.1(3.8)$ & $54.6(7.9)$ & $30.7(5.9)$ \\
4 years & & $34.2(6.1)$ \\
\hline
\end{tabular}

What was counted as inaccurate responses included non-target aspect or tense markers such as the perfective -ass-(e.g. kki-ess 끼었 is wearing(gloves)'; anc-ass 앉았 is sitting') in the resultative context and the present tense(e.g. anc-nun 앉는 'is sitting'; ppet-e 뻗어 has stretched(arms)') in the resultative or perfective context. The alternative form children used most often was the perfective -ass-, which in fact can express result state meaning by implicature as discussed earlier. For the generally low use of the resultative - $a$ iss- with the verbs of state change(e.g. 부러지다 'break', 붙다 'stick', children used the perfective - ass ${ }^{-}$predominantly. In comparison, for the intransitive posture verbs, many children overextended - $k o$ is $S^{-}$to express the result state meaning, instead of - a iss-(e.g. *anc-uko iss 앉으고 있- is sitting'; *nwup--uko iss 누우고 있- is lying on one's back'; *se-ko iss 서고 있- is standing'). Among three year olds, 7 out of 15 children had tokens of such overextension. Coincidentally, 7 out of 14 children in the four year old group too overextended the marker $-k o$ is ${ }^{-}$to resultative contexts. Interestingly, there were two outlying cases, one three-year-old child and one four-year-old child each produced four tokens of $-a$ iss-, which include both grammatical and ungrammatical utterances(e.g. anc-a iss 앉아 있-ís sitting'; se-a iss 서 있-; puth-a iss 붙어 있- is attached'; *tat-a iss 닫아 있- is closed'; *pel-a iss 벌려 있- is open'). Except for these two children, a majority of children used - $k o$ is $s^{-}$more productively for resultative meaning in both age groups.

Compared to comprehension(compare Table 1 with Figure 3), the child's 
production overall lagged behind comprehension for both imperfective markers. But by 4 years of age, the production for $-k o$ iss- marker is more developed than - a iss- marker. For perfective marker - ass-, it appears that both 3 and 4 years olds were quite stable in using it in both comprehension and production.

\section{Conclusion and Discussion}

Our study aimed to illuminate how Korean-learning children develop two imperfective markers that present an interesting case: whether children first extend the use of progressive $-k o$ iss $s^{-}$to the resultative first, followed by acquiring a new form, $-a$ iss- associated with result state description.

In comprehension, both 3 and 4-year-olds appeared fairly good at understanding these imperfective markers, their performance quite comparable to perfective marker - ass ${ }^{-}$. However, 4-year-olds were more accurate than 3-year-olds, showing a progression of understanding of these markers with age. When resultative - ko iss- understanding was compared with progressive - ko iss ${ }^{-}$, both age group showed that their understanding was superior with progressive, consistent with prior findings(Shin, 2005).

While behavioral data(i.e., picture selection accuracy) showed comparable comprehension abilities between the two imperfective markers, eye-fixation pattern observed during sentence-listening suggested that children may be faster in identifying resultative - $k o$ is $S^{-}$than resultative - a is $S^{-}$because their looks to the target converged earlier to resultative - ko iss- target than resultative - a iss $s^{-}$target(see Figure 4A-B). However, eye-gaze data are currently only partial and thus suggestive of these patterns. Further study would be needed to corroborate this difference.

By comparison, the results of the production task established the precedence of the resultative - $k o$ iss- over $-a$ iss- more clearly, confirming our second hypothesis about polysemous extension of the 
progressive - $k o$ iss- as the more likely acquisition mechanism. While 3-year-olds are not yet producing both markers accurately, 4-year-olds became more accurate with - ko iss- than - a iss- marker. At the same time, we observed that children's production of the imperfective markers overall lag behind their comprehension, being in line with the pattern typically observed in other areas of first language acquisition(Hoff, 2014).

Regarding the three working hypotheses we set out to test, we found our data lend support to all three hypotheses: (i) as predicted by Aspect Hypothesis(Anderson and Shirai, 1996) and prior studies, the progressive meaning of -ko iss- develops before the resultative meaning, as confirmed in our comprehension data. (ii) It appears that the meaning of - $k o$ iss- expands to the resultative before learning the use of $-a$ iss-. Our production data shows that by age 4, children begin to use the resultative meaning of ${ }^{-k} \mathrm{ko}_{\text {iss- }}$ more accurately than - a iss-, suggesting that such expansion begins around the age of 4 . These results support the idea that Korean-learning children's development imperfective aspect marking emerges with polysemous extension of the familiar form before they acquire a new form. (iii) Lastly, we observed that children's understanding and use of the markers varied by lexco-grammatical environment. In particular, we observed overgeneralization of - $k o$ iss- to the context of - a iss ${ }^{-}$, in which intransitive verbs are used to describe posture(e.g., 'is sitting', 'is lying on one's back'). These observations lend support for our third hypothesis that the resultative $-k o$ iss- is over-extended to intransitive verbs initially and that learning of lexico-grammatical contexts of $-k o$ iss ${ }^{-}$and $-a$ iss ${ }^{-}$would be gradual over time.

As we discussed earlier, no study thus far has looked at L1 acquisition pattern of aspect morphology in Korean closely, while L2 acquisition has been better documented(Lee and Kim, 2007; Ryu et al., 2016). Our data is the first to document detailed developmental patterns of imperfective aspect marking that occur around the age three and four both in comprehension and production, together with eye-fixation patterns. Interestingly, what we observed in L1 acquisition is quite similar to L2 
acquisition pattern in many ways. As Ryu et al.(2016) showed that Japanese learners of Korean acquired resultative - $k o$ iss - before - a iss-, based on the familiar/similar form used in Japanese (i.e., -te iru-). Lee and Kim(2007) also reported that English learners of Korean appeared to follow principle of polysemy rather than principle of isomorphism although their data was rather mixed to provide a definitive conclusion. Perhaps, whether L1 or L2, acquisition of morphology might follow a parallel progression due to the ease of extending meaning of a familiar form as compared to learning a completely unfamiliar form.

However, such developmental progression is somewhat contradictory to general lexical development pattern. Early on, toddlers appear to follow principle of isomorphism (also known as mutual exclusivity assumption, Markman and Wachtel, 1988) unless the child is exposed to multilingual environments(Byers-Heinlen and Werker, 2009). And as they acquire more words and develop linguistic awareness, they overcome this assumption (or bias) to become able to learn meanings of polysemous words (Srinivasan and Snedeker, 2011). And yet, in the development of imperfective marking, we observed somewhat opposite pattern. What these would indicate is that we would need further corroboration with more developmental data in other languages to see if this pattern in morphology holds across languages.

주제어: 상 형태론, 발달, 한국어, 이해, 산출, 응시 패턴, 비완료상, 결과상

\section{References}

Andersen, R. W. and Y. Shirai. 1996. Primacy of Aspect in First and Second Language Acquisition: The Pidgin/creole Connection. In Ritchie, W. C. and T. K. Bhatia (Eds.), Handbook of Second Language Acquisition. San Diego, CA: Academic Press. 527-570.

Bardovi-Harlig, K. 2005. Tracking the Elusive Imperfect in Adult L2 Acquisition: Refining the Hunt. In Kempchinsky, P. and Slabakova, R. (eds.), Aspectual Inquiries. Amsterdam: Springer. 397-419. 
Byers-Heinlein, K. and J. Werker. 2009. Monolingual, Bilingual, Trilingual: Infants' Language Experience Influences the Development of a Word Learning Heuristic. Developmental Science 12(5), 815-823.

Fried, M. 2007. Constructing Grammatical Meaning: Isomorphism and Polysemy in Czech Reflexivization. Studies in Language 31, 721 - 764.

Hoff, E. 2014. Language Development.(5th edition). Belmont, CA: Wadsworth. Jeong, S. 2013. A Study on a Scalar Approach and a Syntactic Model in English Aspectual Classes. Journal of Language Sciences 20(2), 189-212.

Kim, J. 2013. Aspectual Properties of the Korean Imperfective Constructions. Language and Linguistics 14(6), 1035-1074.

Kim, M. 2009. The Intersection of the Perfective and Imperfective Domains: A Corpus-based Study of the Grammaticalization of Korean Aspectual Markers. Studies In Language 33(1), 175-214.

Lee, E. 2008. Argument Structure and Event Structure: the Case of Korean Imperfective Constructions. Journal of East Asian Linguistics 17, 117-139.

Lee, H. S. 1991. Tense, Aspect and Modality; A Discourse-pragmatic Analysis of Verbal Suffixes in Korean from a Typological Perspective. Unpublished Doctoral Dissertation.University of California, Los Angeles.

Lee, K. 1993. A Korean Grammar on Semantic-pragmatic Principles. Seoul : Hankwuk Mwunhwasa.

Lee, E. H. and H. Y. Kim. 2007. On Cross-linguistic Variations in Imperfective Aspect: The Cse of L2 Korean. Language Learning 57, 651-685.

Markman, E. M. and G. F. Wachtel. 1988. Children's Use of Mutual Exclusivity to Constrain the Meanings of Words. Cognitive Psychology 20(2), 121-157.

Oh, S. Y. 2003. The Korean Verbal Suffix -ess A Diachronic Account of its Multiple Uses. Journal of Pragmatics 35, 1181 - 1222.

Shin, K. S. 2005. The Acquisition of Tense and Aspect in Child Korean. Proceedings of the Annual Boston University Conference on Language Development 29(2), 528-539.

Shirai, Y. and R. W. Andersen. 1995. The Acquisition of Tense-aspect Morphology: A Prototype Account. Language 71, 743-762.

Smith, C. S. 1991. The Parameter of Aspect. Dordrecht : Kluwer.

Smith, C. S. 1997. The Parameter of Aspect(2nd edition). Dordrecht : Kluwer Academic Publishers. 
Srinivasan, M. and J. Snedeker. 2011. Judging a Book by its Cover and its Contents: The Representation of Polysemous and Homophonous Meanings in Four-year-old Children. Cognitive Psychology 62, 245-272.

Ryu, J.-Y., K. Horie and Y. Shirai. 2016. Acquisition of the Korean Imperfective Aspect Markers - ko iss - and - a iss - by Japanese Learners: A Multiple-factor Account. Language Learning 65, 791-823.

Tanenhaus, M. K., M. J. Spivey-Knowlton and J. C Sediviy. 1995. Integration of Visual and Linguistic Information in Spoken Language Comprehension. Science 268(5217), 1632.

Yoon, Y. 2015. The Perfect Meaning of Korean Revisited. Journal of Language Sciences 224), 241-266.

Zawada, B. 2007. Conceptual Integration and Intercategorical Polysemy. Language Matters 38, 150-175

Hae-Young Kim

Duke University

Department of Asian and Middle Eastern Studies

Box 90414

2204 Erwin Rd.

Durham, NC 27708, U.S.A.

Tel: 01-919-660-4364

E-mail: haeyoung@duke.edu

Youngon Choi

Chung-Ang University

Department of Psychology

Heukseok-ro 84, Dongjak-gu

Seoul 06794, Korea

Tel: 02-820-5898

E-mail: yochoi@cau.ac.kr

Received: 2016. 09. 30

Revised: 2016 11. 16

Accepted: 2016. 11. 20 